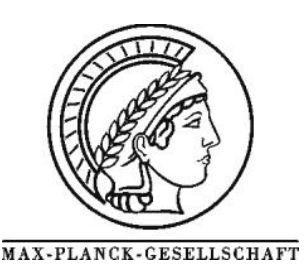

\title{
Promotion effect in Pt-ZnO catalysts for selective hydrogenation of crotonaldehyde to crotyl alcohol: a structural investigation
}

\author{
A. D. Wang ${ }^{1}$, F. Ammari ${ }^{2}$, R. Touroude ${ }^{2}$, D.S. Su ${ }^{1, *}$, R. Schlögl ${ }^{1}$ \\ ${ }^{1}$ Fritz-Haber-Institut der Max-Planck-Gesellschaft, Faradayweg 4-6, Berlin 14195, Germany \\ ${ }^{2}$ LMSPC-UMR 7515 du CNRS, ECPM-ULP, Strasbourg, France \\ * Corresponding author: e-mail dangsheng@ @ fhi-berlin.mpg.de, Tel.: +49-30-8413-5406; fax: +49-30-8413-4401
}

Available online 13 December 2008.

\begin{abstract}
Pt-ZnO catalysts prepared from different precursors, $\mathrm{H}_{2} \mathrm{PtCl}_{6}$ and $\mathrm{Pt}\left(\mathrm{NH}_{3}\right)_{4}\left(\mathrm{NO}_{3}\right)_{2}$, and reduced at increased temperatures are used to achieve high selectivity towards crotyl alcohol in hydrogenation of crotonaldehyde. The ex-chloride catalyst shows a higher activity and selectivity than the ex-nitrate one. Transmission electron microscopy, electron diffraction, high-resolution imaging, energy dispersive X-ray spectroscopy and element mapping are used to characterize the catalysts in order to correlate the microstructure to the catalytic behavior. PtZn alloy formation is confirmed for both ex-chloride and ex-nitrate catalysts reduced at $673 \mathrm{~K}$. The metal particles in ex-nitrate catalyst are smaller in size than those in exchloride. In most aggregates of the ex-chloride catalyst, chlorine is distributed homogeneously with low concentration $(<1 \%)$. The higher chlorine concentration in some region leads to local morphology and microstructure changes. Influences of the observed structural features such as alloy formation, particle size difference, formation of ill-defined material, and chlorine distribution are discussed.
\end{abstract}

Keywords: Crotyl alcohol; PtZn alloy; Electron diffraction; High-resolution electron microscopy; Energy dispersive Xray spectroscopy; Element mapping

\section{Introduction}

Unsaturated alcohols are important intermediates for fine chemistry, pharmaceutical and agrochemical production, etc. Selective catalytic hydrogenation of $\alpha, \beta$ unsaturated aldehyde to unsaturated alcohol by using heterogeneous catalysts is of great interest because the heterogeneous catalytic method can facilitate the process, eliminate the waste production and greatly lower the cost compared with using a large amount of reduction agents such as metal hydrides $[1,2]$. However, the challenge is the selective hydrogenation of carbonyl bonds leaving the olefinic bonds unaffected, which are thermodynamically more favored for reduction. Monometallic catalysts supported on non-reducible support usually lead to formation of saturated aldehyde [3, 4]. In order to achieve a high selectivity towards unsaturated alcohol, the catalysts must be modified by the addition of promoters, by introducing a second metal and/or using a functional support, which may exhibit either steric effects or electronic effects on the metal particles [2, $5]$.

A wide range of catalysts has been studied to elucidate the factors that could have influences on the selectivity to unsaturated alcohol in the hydrogenation of $\alpha, \beta$ unsaturated aldehyde. For the platinum-based bimetallic catalysts, some electropositive metals, such as Fe, Sn, Zn, $\mathrm{Ni}$ and Co, etc., have prominent promotion effects [6-13]. For example, $\mathrm{Pt}_{80} \mathrm{Fe}_{20}$ alloy was reported to enhance the activity and the selectivity of carbonyl bond hydrogenation on its (111) surface. Surface Fe was ascribed to have the effect of weakening the $\mathrm{C}=\mathrm{O}$ bond by a specific ion interacting with the $\mathrm{O}$ atom [6]. Pt-Sn catalysts on various supports have been extensively studied [7-10]. Oxidised $\mathrm{Sn}$ species were suggested to benefit the hydrogenation of the 

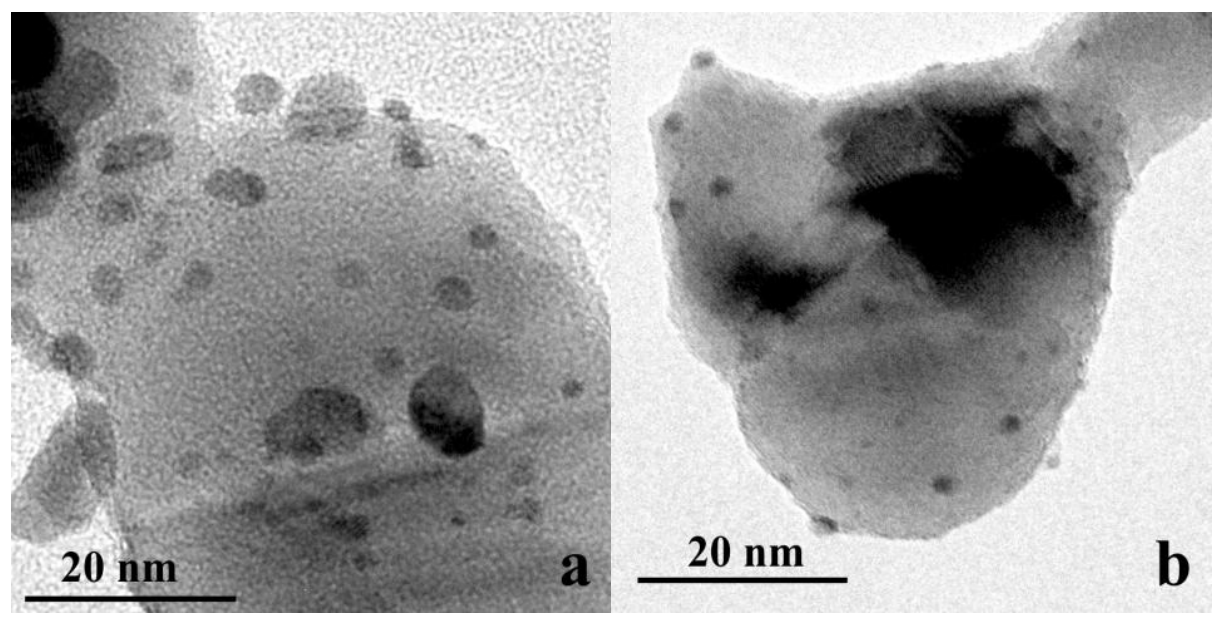

Fig. 1: TEM image of overview of (a) the ex-chloride catalyst and (b) the ex-nitrate catalyst.

carbonyl bond. In addition, the PtSn alloy formation was speculated to also change the electronic structure of $\mathrm{Pt}$, which may hinder the adsorption of olefinic bond. Similar alloy effects were suggested to be operational in the PtZn and PtNi alloy systems [11, 12].

The reactivity of metal particles can be controlled through metal-support interactions, which are introduced during the reduction treatment of the catalyst. Some reducible supports, such as $\mathrm{TiO}_{2}, \mathrm{CeO}_{2}$ and $\mathrm{SnO}_{2}$, were used to promote the hydrogenation of carbonyl bond by creating sites at the interface between the metal particle and suboxide species from the support, which decorate the particle surfaces [14-18]. The reduction of support also leads to alloy formation, as observed in $\mathrm{Pt}-\mathrm{ZnO}$ and $\mathrm{Pt}-\mathrm{SnO}_{2}$ systems. An increase in selectivity to the unsaturated alcohol is usually accompanied with such alloy formation.

Recently, Pt particles supported on $\mathrm{ZnO}$ were found to exhibit high performance in the selective hydrogenation of crotonaldehyde towards crotyl alcohol when using metal precursor $\mathrm{H}_{2} \mathrm{PtCl}_{6}$ [19-21]. The residual chloride was suggested to play an important role. The catalytic reaction using the catalysts with the same preparation procedure was reported in $[19,20]$. The ex-chloride $1 \% \mathrm{Pt}$ catalyst shows high selectivity $(80-90 \%)$ towards crotyl alcohol in a range of conversion 9-23\% after $673 \mathrm{~K}$ reduction. The ex-nitrate $1 \% \mathrm{Pt}$ catalyst reduced at the same temperature has a much lower selectivity of $47 \%$ with $5 \%$ conversion [20]. For the $5 \%$ Pt catalysts, the ex-chloride one is also much more selective ( $81 \%$ after $673 \mathrm{~K}$ reduction) than the ex-nitrate one (49\% after $673 \mathrm{~K}$ reduction), both with a conversion range from 5 to $20 \%$ [19]. All the selectivity and conversion were measured at the stabilized stage in time on stream. These catalysts were previously characterized by various techniques, including temperature programmed reduction, X-ray diffraction (XRD), transmission electron microscopy (TEM), X-ray photoelectron spectroscopy (XPS) and Fourier transformation infrared spectroscopy (FTIR), etc [19, 20]. The formation of PtZn after reduction at increased temperatures was observed by XPS and XRD. For the ex-chloride catalyst, pyridine adsorption indicated an enhanced Lewis acidity on the support. In order to further elucidate the influence of chloride to the improvement of selectivity, the distribution of chlorine and the local structure of the chlorine-rich region are of great importance. However, due to low concentration, little has been known on the chlorine distribution in such catalysts.

In transmission electron microscope, by converging the electron beam into the size of several nanometers, chemical information can be retrieved from the very local area in the sample. Mapping techniques, by energy dispersive X-ray spectroscopy (EDX) in scanning transmission electron microscopy (STEM) mode or energy filtering TEM, offer the further possibility to obtain spatially resolved chemical and electronic information. In addition, metal particles size distribution, metal-support interaction and defect structures, etc. can also be studied by TEM techniques. In the present paper, TEM, electron diffraction, high-resolution imaging and EDX are used to characterize the ex-chloride and comparatively ex-nitrate catalysts of $\mathrm{Pt}$ supported on $\mathrm{ZnO}$. Structural differences for the two catalysts and the chlorine distribution in the ex-chloride catalyst are studied to reveal the structure-property correlations.

\section{Experimental}

The catalysts of $1 \mathrm{wt} \%$ and $5 \mathrm{wt} \% \mathrm{Pt}$ supported on $\mathrm{ZnO}$ are prepared by impregnation of commercial $\mathrm{ZnO}$ (Asturienne des Mines, $42.6 \mathrm{~m}^{2} / \mathrm{g}$ ) with an aqueous solution of $\mathrm{H}_{2} \mathrm{PtCl}_{6}$ or $\left[\mathrm{Pt}\left(\mathrm{NH}_{3}\right)_{4}\right]\left(\mathrm{NO}_{3}\right)_{2}$ (Strem Chemicals), followed by evaporation of water and drying overnight at 393 $\mathrm{K}$. Then the samples were calcined in air (760 Torr) at 673 $\mathrm{K}$ for four hours and reduced in $\mathrm{H}_{2}$ at $673 \mathrm{~K}$ for four hours. BET results show that after calcination, the $\mathrm{ZnO}$ surface area is about $24.6 \mathrm{~m}^{2} / \mathrm{g}$. It has not changed after platinum salt impregnation, for both the ex-chloride and the exnitrate catalysts. After $673 \mathrm{~K}$ reduction, the surface area decreased significantly on the ex-chloride catalysts $(9.0$ $\mathrm{m}^{2} / \mathrm{g}$ ), but changed much less on the ex-nitrate catalysts $\left(18.3 \mathrm{~m}^{2} / \mathrm{g}\right)$. The powder samples were dispersed in ethanol 
and mounted onto copper grids covered with holey carbon film for TEM observations by a Philips CM200 FEG microscope. EDX analysis was performed on a Philips CM200 LaB6 microscope using a DX 4 analyzer system (EDAX). Element maps of $\mathrm{Pt}, \mathrm{Zn}$ and $\mathrm{Cl}$ were acquired by EDX in STEM mode.

\section{Results}

\subsection{Overview}

Increasing loading from $1 \%$ to $5 \%$ of Pt does not affect significantly the catalyst morphology and microstructure. The structural difference between the ex-chloride and the ex-nitrate catalysts is more distinguished. Figs. 1a and $1 \mathrm{~b}$ show the overview images of ex-chloride and ex-nitrate samples, respectively. For the ex-chloride sample, most particles are larger than $3 \mathrm{~nm}$ and some are as large as 10 nm. In contrast, most particles of the ex-nitrate are about 2$3 \mathrm{~nm}$ large or even smaller.

\subsection{Electron diffraction}

The representative selected area electron diffraction pattern from the $5 \% \mathrm{Pt} / \mathrm{ZnO}$ ex-chloride catalysts is shown in Fig. $2 \mathrm{a}$ and the intensity profile is plotted in Fig. 2b. The sharp rings indicate that the catalysts are well crystallized. The lattice spacings corresponding to these rings are calculated and are compared with the possible known phases. Most of the diffraction rings can be attributed to hexagonal $\mathrm{ZnO}$ (zincite). Some strong diffractions are indexed in Fig. 2b. By calibrating the diffraction pattern using $\mathrm{ZnO}$ intensities, the radius, thereofore the corresponding lattice spacings, of other rings or spots can be obtained precisely. The intensities corresponding to $d=2.21 \AA$ and $d=2.0 \AA$ (indicated by the arrows in Fig. $2 a$ and $2 b$ ) can be calculated and they coincide with (101) and (110) diffractions of tetragonal PtZn alloy. For the $1 \% \mathrm{Pt} / \mathrm{ZnO}$ ex-chloride catalyst, the $\mathrm{PtZn}$ diffractions are also visible but weaker than those from the $5 \% \mathrm{Pt}$ catalyst. This is simply due to the lower Pt load.

The $5 \% \mathrm{Pt} / \mathrm{ZnO}$ ex-nitrate catalyst reduced at $673 \mathrm{~K}$ shows diffraction pattern as in Fig. 2c. The intensity profile along the radius is plotted in Fig. 2d. All the sharp peaks can be assigned to $\mathrm{ZnO}$ but no diffractions from PtZn can be distinguished in Fig. 2c. Only from the profile in Fig. $2 \mathrm{~d}$, a shoulder (indicated by arrow) at the right side of $\mathrm{ZnO}$ (101) diffraction is just noticeable and it corresponds to the lattice spacing of about $2.22 \AA$, which can be attributed to PtZn (101) diffraction. The very weak and diffuse intensities of PtZn in electron diffraction pattern are likely due to the very small particle size, which coincides with the TEM observation.
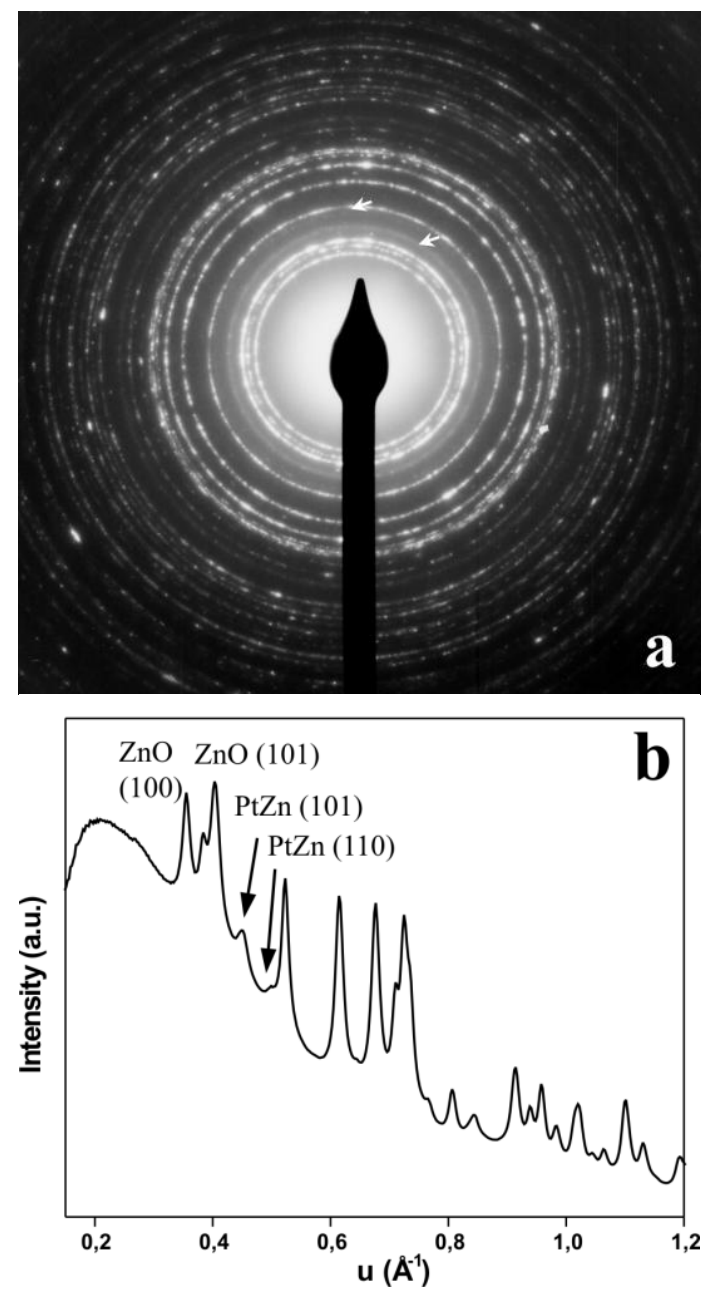

Fig. 2: Selected area electron diffraction pattern (a) from the exchloride catalyst and (c) from the ex-nitrate catalyst, both reduced at $673 \mathrm{~K}$. (b) and (d) are corresponding intensity profiles, respectively.

\subsection{HRTEM}

HRTEM images are taken from the $\mathrm{ZnO}$ support and from the particles to reveal the local structures in the catalysts.

Fig. 3a shows a HRTEM image of a single PtZn alloy particle in the $5 \% \mathrm{Pt} / \mathrm{ZnO}$ ex-chloride catalyst. From the corresponding FFT pattern, the sets of lattice spacings can be calculated and the particle is identified to be tetragonal PtZn $(\mathrm{a}=\mathrm{b}=2.86 \AA, \mathrm{c}=3.51 \AA$ and space group $\mathrm{P} 4 / \mathrm{mmm}$ ) viewed along its [001] zone axis. The sets of lattice planes indexed in the FFT correspond to (100) and (010) planes, respectively. Most of the particles exhibit lattice fringes that can be attributed to PtZn but the shape of these alloyed particles varies.

A representative HRTEM image of the small particle in the $5 \% \mathrm{Pt} / \mathrm{ZnO}$ ex-nitrate catalyst is shown in Fig. $3 \mathrm{~b}$. The lattice fringes on the support correspond to $\mathrm{ZnO}(100)$ planes with spacing of $2.81 \AA$. It can be used to calibrate the magnification of the image so that the lattice spacings on the particle can be measured precisely. Thus obtained value is about $2.23 \AA$, very close to PtZn (101) planes spac 


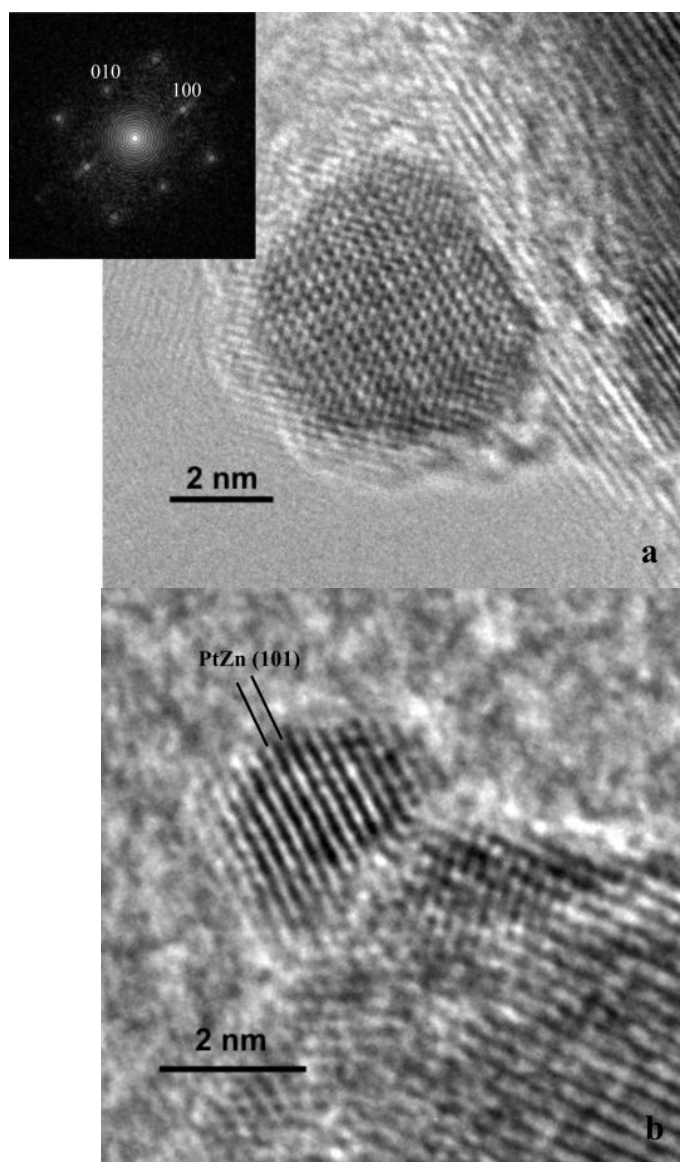

Fig. 3: HRTEM images of (a) a PtZn alloy particle in the exchloride catalyst on [001] zone axis, with FFT inset. (b) A small PtZn alloy particle with size of about $2 \mathrm{~nm}$ in the ex-nitrate catalyst.

ing $2.22 \AA$, rather than Pt (111) spacing, which has a value of $2.265 \AA$. Occasionally big particles were observed with the lattice spacings also belong to PtZn alloy. This result furthermore confirms the existence of PtZn in the ex-nitrate catalyst, which is in agreement with our electron diffraction results and the previous XRD and XPS studies [19].

\subsection{Cl distribution in the ex-chloride catalyst}

EDX and element mapping in STEM mode are used to detect chlorine concentration and its distribution in the $1 \%$ and $5 \% \mathrm{Pt} / \mathrm{ZnO}$ ex-chloride catalyst. In both catalysts, The residual $\mathrm{Cl}$ concentration in the catalysts after the reduction at $673 \mathrm{~K}$ is of two different levels. Generally the concentration is below $1 \%$ for the catalysts with $1 \%$ and 5 $\% \mathrm{Pt}$ load. In most cases, $\mathrm{Zn}, \mathrm{Pt}$ and $\mathrm{Cl}$ distributions in the agglomerates are like the element maps shown in Fig. 4, which was taken from the $5 \% \mathrm{Pt} / \mathrm{ZnO}$. All the three elements distribute homogeneously over the agglomerate. In a less frequently observed case, regions with a $\mathrm{Cl}$ concentration much higher than the average value can be found. The STEM image and element maps of $\mathrm{Zn}, \mathrm{Pt}$ and $\mathrm{Cl}$ taken from such a $\mathrm{Cl}$-rich region in $5 \% \mathrm{Pt} / \mathrm{ZnO}$ catalyst are shown in Fig. 5a. As measured in the EDX spectrum shown in Fig. 5b, the local $\mathrm{Cl}$ concentration corresponding to the agglomerate in Fig. 5a is about $3.6 \%$. The $\mathrm{Zn}$ and $\mathrm{Pt}$ maps in Fig. 5a indicate a homogeneous distribution of the detected elements, similar to that observed in other parts of the catalyst. The $\mathrm{Cl}$ map in Fig. 5a obviously shows higher concentration in the middle part of the image than in the

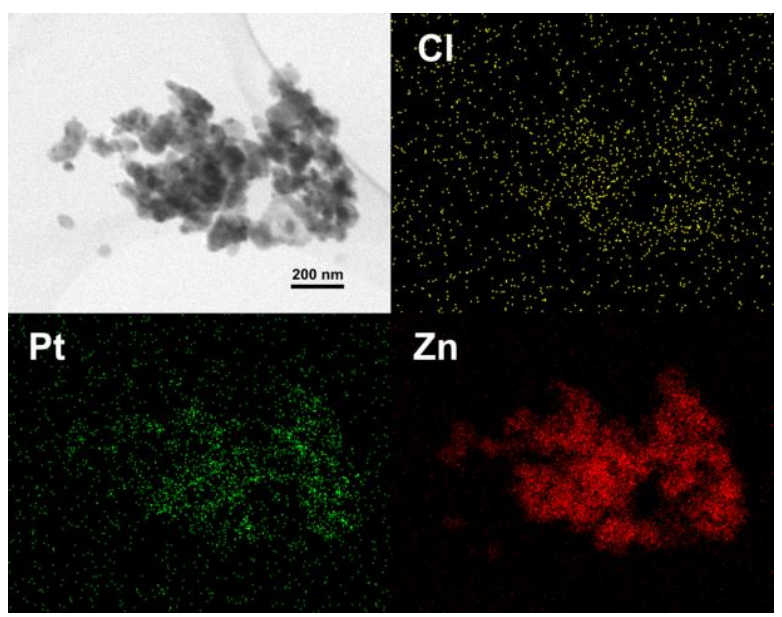

Fig. 4: STEM image and $\mathrm{Cl}, \mathrm{Pt}$ and $\mathrm{Zn}$ element maps from agglomerate with $\mathrm{Cl}$ concentration below $1 \%$.
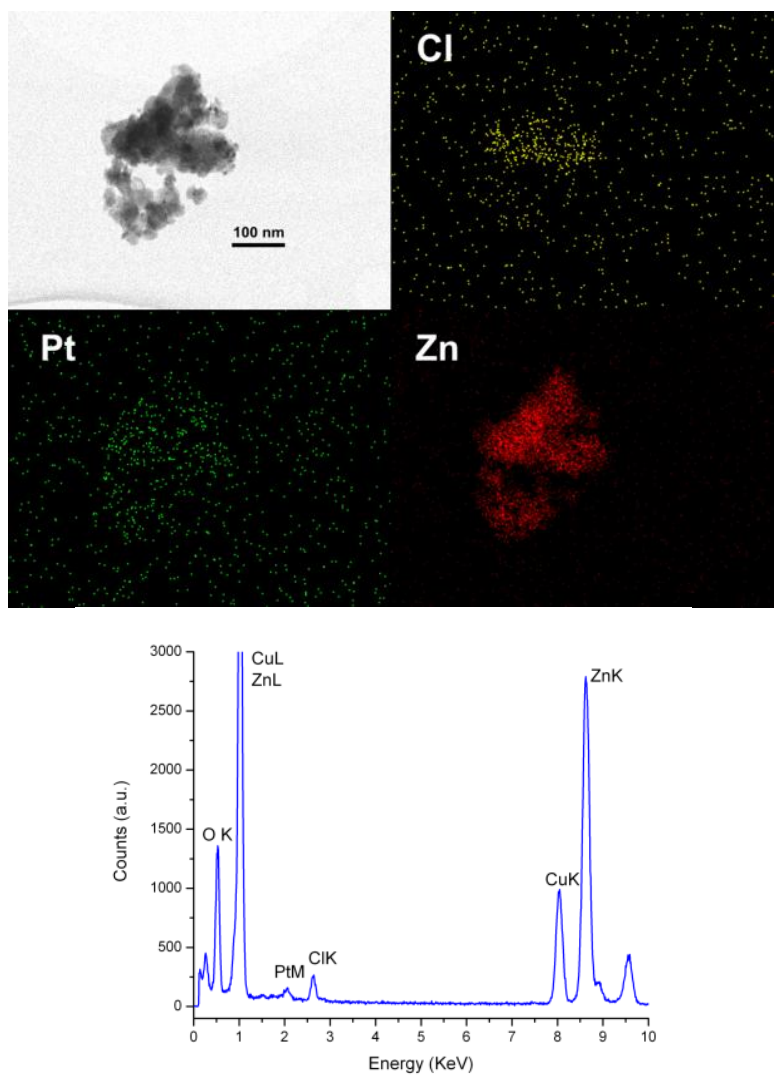

Fig. 5: (a) STEM image and $\mathrm{Cl}, \mathrm{Pt}$ and $\mathrm{Zn}$ element maps from agglomerate with $\mathrm{Cl}$ concentration of about $3.6 \%$. The $\mathrm{Cl}$ map shows an area with obvious higher $\mathrm{Cl}$ concentration than the neighboring parts. (b) The corresponding EDX spectrum from the Cl-rich region. 


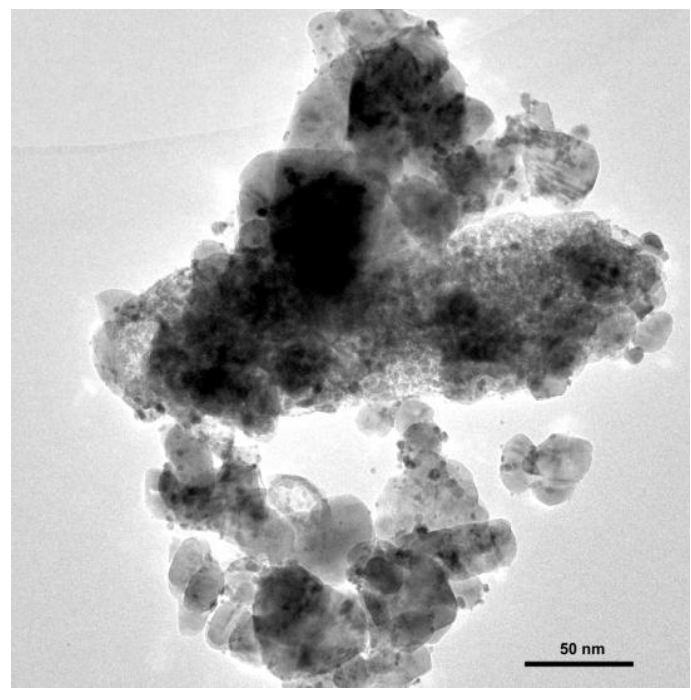

Fig. 6: TEM image of the same agglomerate as in Figure 6a. The $\mathrm{Cl}$-rich area is revealed to be highly porous and contains nanocrystallites and amorphous stuffs.

neighboring parts. The higher $\mathrm{Cl}$ concentration is accompanied with a different morphology and microstructure as revealed by TEM and HRTEM.

Fig. 6 is a higher magnification TEM image taken from the same agglomerate as shown in Fig. 5a. The contrast in the $\mathrm{Cl}$-rich part is obviously different from the neighboring parts, indicating that the region is highly porous and consists of nanocrystals as apposed to the microcrystalline platelets constituting the rest of the agglomerate. The TEM images on other Cl-rich areas for both $1 \%$ and 5\% Pt ex-chloride catalysts reveal similar structures but such structure was never observed in any ex-nitrate catalysts. Representatively, a HRTEM image of the nanocrystalline material in 5\% Pt/ZnO catalyst is shown in Fig. 7a. The FFT of the image (Fig. 7a inset) indicates that all the resolved lattice spacings can be attributed to $\mathrm{ZnO}(100)$ and (002) reflections. No other crystallized phases are detected. In some cases, nanocrystalline filler is embedded in a more or less amorphous binder phase as seen in Fig. $7 \mathrm{~b}$ (circle area for binder phase). This phase must be rich in chlorine and may constitute $\mathrm{Zn}, \mathrm{O}$ and $\mathrm{Cl}$.

\section{Discussion}

Many factors, such as metal specificity, particle size and property of support, may influence the selectivity to unsaturated alcohol on supported metal particles [2, 5]. For the present investigation on $\mathrm{Pt}-\mathrm{ZnO}$ system, the preparation methods, mainly the different precursors used, produce distinct difference in selectivity of the catalysts. Such different behaviors are reasonably correlated with the composition of the metal particles, morphology of the catalysts and/or the structure modification introduced by different precursors. In view of electron microscopy, the structural

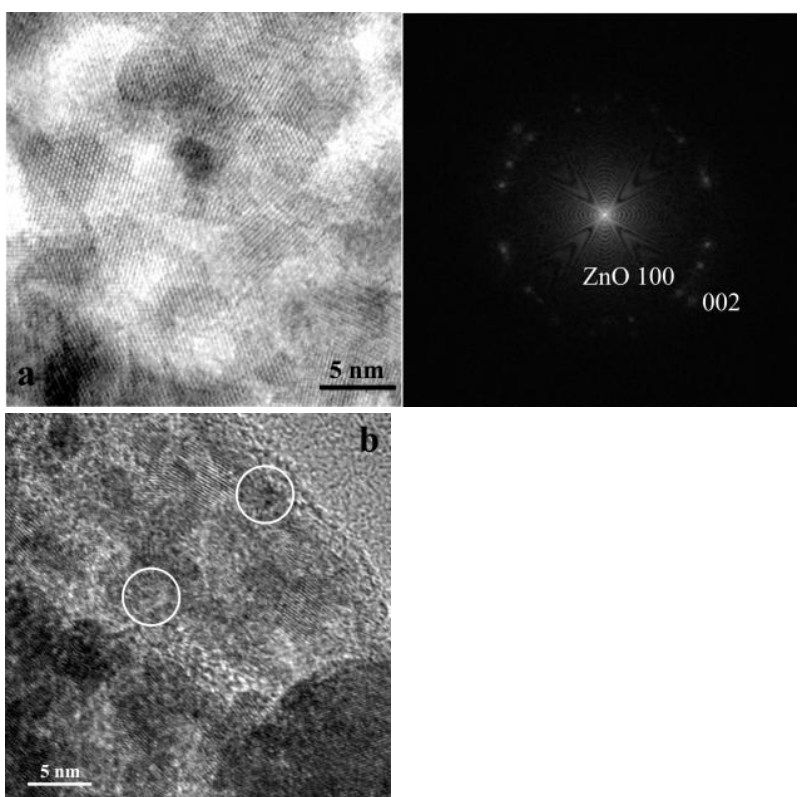

Fig. 7: HRTEM images of (a) randomly oriented nanocrystallites and (b) amorphous region in $\mathrm{Cl}$-rich area.

information from the catalysts offers important keys to understand the catalytic behaviors.

By electron diffraction and HRTEM, the formation of PtZn alloy has been directly verified in the ex-chloride catalyst. For the ex-nitrate catalyst, the characteristic diffractions of PtZn are far less intensive and sharp, indicating very small size of the metal particles. TEM images of the ex-nitrate catalyst also reveal that most particles on the support have the size of about 2-3 $\mathrm{nm}$. Comparatively, the metal particle size of the ex-chloride catalyst is much larger. Precise measurement on lattice fringes in the HRTEM images of ex-nitrate catalyst also shows the existence of PtZn alloy. The TEM observation is in agreement with the XPS studies, in which a narrowing of the Lorentzian half width of the $\operatorname{Pt}\left(4 \mathrm{f}_{7 / 2}\right)$ line was seen as a sign of formation of alloy [20]. One difference between the ex-chloride and the ex-nitrate catalysts is that for the ex-chloride one, alloy is formed at the reduction temperature of $473 \mathrm{~K}$ already, while for the ex-nitrate one, it is formed at higher reduction temperature of about $573 \mathrm{~K}$ [20]. However, for both exchloride and ex-nitrate catalysts, an improvement in selectivity is observed parallel to the formation of PtZn alloy with the increase of reduction temperature. Therefore, alloy formation can promote the catalysts towards higher unsaturated alcohol selectivity, no matter the precursor used. The promotion mechanism is previously attributed to the increased electronic density in PtZn alloy by forming $\mathrm{Pt}^{\delta-}-\mathrm{Zn}^{\delta+}$ entities [19]. However, controversial results indicate that charge transfer between Pt $5 d$ and $6 s, 6 p$ orbitals may occur and lead to the depletion of Pt $5 \mathrm{~d}$ electron population, which weakens the adsorption of $\mathrm{CO}$ on $\mathrm{Pt}$ [22]. Such charge transfer may also modify the adsorption mode of crontonaldehyde by binding the electron pair of terminal oxygen with the holes in Pt d band. Importantly, depending on the reduction temperatures and preparation procedures 
the reduced $\mathrm{ZnO}_{\mathrm{x}}$ species may interact with the supported metal, resulting in modification of electronic density of the metal [23-25]. According to our present observation, the zinc chloride or oxychlorinated species in ex-chloride catalysts may have similar interaction with Pt.

The $\mathrm{Cl}$ promotion effect can be attributed to two factors. Firstly, the fact that PtZn alloy formation takes place at a lower temperature for the ex-chloride catalyst than for the ex-nitrate one implies that chlorine facilitates the formation of PtZn alloy during reduction. Secondly, the present observation of $\mathrm{Cl}$ distribution by element mapping reveals a general distribution of less than $1 \%$ in the exchloride catalysts. This could be related with the FTIR study of pyridine adsorption on both ex-chloride and exnitrate catalysts, which indicate that the ex-chloride catalyst has a higher Lewis acidity on the support [20]. Lewis acid sites can act as centers for adsorbing the $\mathrm{C}=\mathrm{O}$ bond of unsaturated aldehyde through the lone pair of electrons from oxygen. Higher $\mathrm{Cl}$ concentration was found in both of the low load and the high load Pt ex-chloride catalysts. By element mapping and corresponding (HR)TEM images, Clrich area exhibits highly porous morphology and smaller grains of $\mathrm{ZnO}$ in contrast to other area, as well as some amorphous stuff, which could be zinc chloride or oxychlorinated species of $\mathrm{Zn}$. Such structure was not observed in any ex-nitrate catalysts. This indicates that high concentration of chlorine has great influences in the local morphology of the catalysts. The $\mathrm{Cl}$ promotion effect was recently also proved by the similar high selectivity observed on the $\mathrm{Pt} / \mathrm{ZnCl}_{2} / \mathrm{SiO}_{2}$ system [26]. The probable existence of $\mathrm{Cl}$ rich amorphous stuff is expected to further change the property of the support locally.

In the present case, we are not inclined to attribute the selectivity to particle size effect, though. The particle size of the ex-chloride catalyst is much bigger than that of the ex-nitrate one. This is mainly because of the experimental result from another ex-nitrate catalyst prepared by the same group, which has similar composition but different particle size, exhibiting similar catalytic behaviors [19]. Considering the roughness and the irregular shape of the observed particles for both ex-chloride and ex-nitrate cata-

\section{References}

[1] P.N. Rylander, Catalytic hydrogenation over Platinum Metal, Academic Press, 1967, New York.

[2] P. Gallezot, D. Richard, Catal. Rev.-Sci. Eng., 40 (1998) 81

[3] R. Touroude, J. Catal., 65 (1980) 110.

[4] P. Claus, Top. Catal., 5 (1998) 51.

[5] V. Ponec, Appl. Catal. A, 149 (1997) 27.

[6] P. Beccat, J.C. Bertolini, Y. Gauthier, J. Massardier, P. Ruiz, J. Catal., 126 (1990) 451.

[7] J.L. Margitfalvi, A. Tompos, I. Kolosova, J. Valyon, J. Catal., 174 (1998)_246.

[8] F. Coloma, J. Llorca, N. Homs, P.R. de la Piscina, F. Rodriguez-Reinoso, A. Sepulveda-Escribano, Phys. Chem. Chem. Phys., 2 (2000) 3063.

[9] A. Huidobro, A. Sepulveda-Escribano, F. Rodriguez-Reioso, J. Catal., 212 (2002) 94. lysts, the proportion of different exposed sites (e.g. terrace vs. edge) is not dominantly determined by the particle size. Furthermore, for crotonaldehyde, the steric effect of the substitution on $\mathrm{C}=\mathrm{C}$ bond is expected to be trivial. All these imply that particle size effect is not a determining factor for the Pt- $\mathrm{ZnO}$ catalysts in the selective hydrogenation of crotonaldehyde. Electronic effects is believed to play essential roles. From the present investigation, the alloy formation and the support electronic property both have influence in local electronic structure of Pt. By using reducible support, controlling reduction temperature and modifying the support acidity by different precursor, the local configuration around Pt could be finely tuned for the optimum selectivity to unsaturated alcohol.

\section{Conclusion}

The present investigation characterizes the exchloride and ex-nitrate Pt-ZnO catalysts by TEM, electron diffraction, high-resolution imaging, EDS and element mapping in STEM mode. PtZn alloy formation is confirmed for both ex-chloride and ex-nitrate catalysts reduced at $673 \mathrm{~K}$. The metal particles in ex-nitrate catalyst have smaller size as evidenced by lacking intensive PtZn alloy diffractions in electron diffraction pattern and TEM observation. There is no direct relationship between the particle size of the catalysts and their selectivity. Residual chlorine plays an important role in promoting the catalysts towards high selectivity to crotyl alcohol. Chlorine concentration was measured by EDX and its distribution was studied by element mapping. In most agglomerates, chlorine with low concentration $(<1 \%)$ is distributed somewhat homogeneously. The promotion effect can be mainly attributed to such low concentration $\mathrm{Cl}$ residual. Higher chlorine concentration was observed in some cases, producing highly porous morphology and small grains of $\mathrm{ZnO}$. Cl-rich amorphous stuff is also observed in such region, which may change the property of support locally.
[10] D.I. Jerdev, A. Olivas, B.E. Koel, J. Catal., 205 (2002) 278

[11] J. Silvestre-Albero, F. Rodriguez-Reinoso and A. SepulvedaEscribano, J. Catal., 210 (2002) 127.

[12] C.G. Raab, J.A. Lercher, J. Mol. Catal., 75 (1992) 71.

[13] A. Borgna, B.G. Anderson, A.M. Saib, H. Bluhm, M. Haevecker, A. Knop-Gericke, A.E.T. Kuiper, Y. Tamminga, J.W. Niemantsverdriet, J. Phys. Chem. B, 108 (2004) 17905.

[14] M. Albert Vannice, B. Sen, J. Catal., 115 (1989) 65.

[15] M. Englisch, A. Jentys, J.A. Lercher, J. Catal., 166 (1997) 25.

[16] A. Sepulveda-Escribano, F. Coloma, F. Rodriguez-Reinoso, J. Catal., 178 (1998) 649.

[17] M. Abid, G. Ehret, R. Touroude, Appl. Catal. A, 217 (2001) 219.

[18] K. Liberkova, R. Touroude, J. Mol. Catal. A, 180 (2002) 221. 
[19] M. Consonni, D. Jokic, D. Yu Murzin, R. Tourounde, J. Catal., 188 (1999) 165.

[20] F. Ammari, J. Lamotte, R. Touroude, J. Catal., 221 (2004) 32.

[21] B. Bachiller-Baeza, A. Guerrero-Ruiz, I. Rodriguez-Ramos, Appl. Catal. A, 192 (2000) 289.

[22] J.A. Rodriguez, M. Kuhn, J. Chem. Phys., 102 (1995) 4279.

[23] F. Boccuzzi, A. Chiorino and G. Ghiotti, Surface Science, 209 (1989) 77.
[24] E.L. Rodrigues, J.M.C. Bueno, Appl. Catal. A, 257 (2004) 201.

[25] E.L. Rodrigues, A.J. Marchi, C.R. Apesteguia, J.M.C. Bueno, Appl. Catal. A, 294 (2005) 197.

[26] F. Ammari, C. Milone, R. Touroude, J. Catal., 235 (2005) 1. 